\title{
Science and Art
}

\author{
Ildefonso Rodríguez Leyva* \\ Especialidad en Neurología, Hospital Central "Dr. Ignacio Morones Prieto", Universidad Autónoma de San Luis Potosí, San Luis Potosí, Mexico
}

Medicine and perhaps neurology, in particular, combines art and science in an exceptional way. Any evaluation of a patient, however, simple what afflicts him is, implies conjunction of activities that will finally lead us to a diagnosis.

The observation of an individual on their arrival to the consultation room or emergency room and listening attentively to the situational approach according to the description of the one who suffers and of those who have witnessed it. The directed interrogation allows the clinician to know the before, the beginning, the evolution, and the current situation and the administered treatments and response to these, the background, and how the systems and organs that have not been affected or have been partially affected are.

Afterward, comes the exhaustive search for signs from head to foot, from cognition, cranial nerves, motricity, sensitivity, cerebellar activity, meningism, and the patient's march; all of this to integrate syndromic, topographic, etiological, final, and differential diagnostics. To make decisions on complementary studies that allow us to demonstrate or deny our diagnostic approaches and to always offer a therapy that in our reach and that of our patient can provide the maximum benefit.

So far, it seems clear that the doctor constantly establishes the application of the scientific method in his practice on a daily basis; he observes, establishes a diagnostic hypothesis, experiments on a therapy based on the semiological conjunction of what was found, and establishes a theory that coincides with the findings in the requested laboratory and image examinations.

To practice medicine appears to be simple work, but it really is not, simply because to know how to evaluate each symptom and sign found, it is necessary to have acquired the epidemiological, anatomical, physiological, genetic, biochemical, molecular, imagenological, hematological, and pharmacological knowledge (among much others).

What we previously treated as a movement disorder called Korea, which together with a pattern of autosomal dominant inheritance and progressive cognitive impairment was then called Huntington's disease, we must now demonstrate to be an alteration in the short arm of chromosome 4 in the huntingtin gene, which will be expressed as an exaggerated number of CAG repetitions (more than 40 ) in the first exon encoding of the protein called polyglutamine. Today, we speak of diseases of channels (channelopathies), proteins (proteinopathies), enzymes, etc. The doctor's work has become complex and enormously challenging because it is not enough to be assisted by a computer to solve a problem, one must also have the needed educational and cultural background.

As if it was not enough, doctors today must also be artists, capable of interpreting in the patient's voice the anxiety he conveys, of scrutinizing the cry of despair he contains, and who, if clever enough, will be able to alleviate and reassure the one who suffers. It is an art to

\section{Correspondence:}

*Ildefonso Rodríguez Leyva

Especialidad en Neurología, Hospital Central

"Dr. Ignacio Morones Prieto"

Date of reception: 28-10-2019

Date of acceptance: 02-11-2019

E-mail:ilrole @yahoo.com.mx
Available online: 04-12-2019 Rev Mex Neuroci. 2019;20(6):253-254 www.revmexneurociencia.com 1665-5044/( 2019 Academia Mexicana de Neurología A.C. Published by Permanyer. This is an open access article under the CC BY-NC-ND license (http:// creativecommons.org/licenses/by-nc-nd/4.0/). 
be empathetic, to find a way to console, and to reassure the one who is afraid to suffer the untreatable. It is an art to know how to listen patiently to a story that at times is lost and to reorient the conversation without giving the impression of no longer wanting to listen or of feeling annoyed by it. It is an art to look into the eyes with contagious serenity, with the honesty that calms, with the joy that comforts, with the cleanliness that gives confidence. It is an art to know how to embrace without smothering, to touch without bothering, to listen for relieving, to see and discover the hidden, to feel the pain of others, to smell the infectious process, and to speak with the wisdom of the learned but with the humility of one who recognizes all his limitations.
It is our work and especially that of the neurologist to put together science and art, and to observe, listen, feel, and draw from memory all stored information that may be of use; correlating data, establishing possibilities and deciding what to offer seeking the well-being of the other with the least possible risk of harm. It is through this challenging work that day by day we get to experience unrepeatable stories, unparalleled challenges, hopes that seem unreachable and miracles that cannot be explained.

Medicine, and especially neurology, is a wonderful profession that allows many of us to feels like our days are always different that our patient is unique and that our life is really full of meaning. 